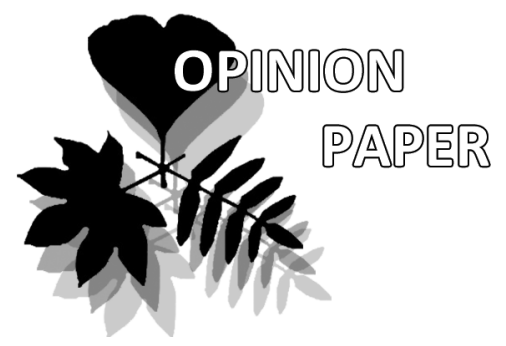

Sviatoslav R. Rybnikov

e-mail: sviatoslav.rybnikov@gmail.com

Zeev M. Frenkel

e-mail: zvfrenkel@gmail.com

Valery M. Kirzhner

e-mail: valery@research.haifa.ac.il

Abraham B. Korol *

e-mail:korol@research.haifa.ac.il

Institute of Evolution,

University of Haifa, Haifa, Israel

* corresponding author

Manuscript received: 06.08.2015

Review completed: 18.09.2015

Accepted for publication: 25.09.2015

Published online: 20.10.2015

\section{Complex Dynamics of Multilocus Genetic Systems: A Revisit of Earlier Findings in Relation to Ecosystem Evolution}

\author{
Sviatoslav R. Rybnikov, Zeev M. Frenkel, Valery M. Kirzhner \& \\ Abraham B. Korol *
}

\begin{abstract}
A B S T R A C T
In our earlier studies on polymorphism and recombination in multilocus genetic systems subjected to cyclical selection, situations were found where allele frequencies demonstrated diverse patterns of complex limiting behavior (CLB). In the present paper, these findings are revisited with respect to their explanatory potential for ecosystem evolution. In particular, we show that the revealed CLB patterns and conditions for their emergence are consistent with key regularities of ecosystem evolution suggested by V.A. Krassilov, namely: (i) ecosystem evolution is irreducible to dynamics of allele frequencies; (ii) release of genetic variation is affected by the type of ecosystem evolution; (iii) ecosystem turnovers are potentially sensitive to dynamics of allele frequencies.
\end{abstract}

Ke ywords : multilocus genetic systems, complex dynamics, ecosystem evolution, polymorphism, recombination

\section{P E 3 Ю M E}

Рыбников С.Р., Френкель 3.М., Киржнер В.М., Король А.Б. Сложная динамика многолокусных генетических систем: анализ ранее полученных результатов в свете эволюции экосистем. В наших преАылущих исследованиях, посвященных полиморфизму и рекомбинации в многолокусных генетических системах, подверженных циклическому отбору, были выявлены ситуации, когАа частоты алмелей демонстрировали разАичные виды сложного предельного поведения (СПП). В Аанной работе рассматривается возможность интерпретации полученных ранее результатов в свете эволюции экосистем. В частности, показано, что обнаруженные виды СПП и условия их возникновения согласуются с основными закономерностями эволюции экосистем, сформулированными В. А. Красиловым, а именно: (i) эволюция экосистем несводима к динамике частот ацлелей; (ii) высвобождение генетической изменчивости определяется характером эволюции экосистем; (iii) смена экосистем может провоцироваться изменениями в Аинамике частот алмелей.

$\boldsymbol{K}_{\boldsymbol{\Lambda}}$ ю ч е в ы е $\mathbf{c} \boldsymbol{\Lambda}$ о в а : многолокусные генетические системы, сложная динамика, эволюция экосистем, полиморфизм, рекомбинация
The modern evolutionary synthesis, developed in 193040 s, has served as a reasonably reliable theoretical base for the 20th century biology. In last decades the theory faces further challenges, both pragmatic and epistemological (Krassilov 2014a), which spurs to rethinking its postulates, in more or less radical manner (Kutschera \& Niklas 2004, Rose \& Oakley 2007, Krassilov 2014b, Laland et al. 2015). However, this paradigm shift appeared rather painful and dilatory. Thus, what Shapiro (2011) describes as 'the 21 st century biology' (e.g., with holism as a philosophic framework, cybernetics as an operation mode, and genome as a focus of heredity theory) still remains a project rather than an implemented program.

Unsurprisingly, theoretical framework for a new evolutionary biology has been sought within open system thermodynamics (Nicolis \& Prigogine 1977, Wicken 1987, Gladyshev 1997). Recently, a profound attempt of such kind has been presented by Krassilov (2014b). Ecosystem evolution was first, to our knowledge, viewed thermodynamically by Weber et al. (1989) and Schneider \& Kay (1994), and later on thoroughly elaborated by Krassilov (1995, 2003, 2014b). Within this approach, one of the central objectives was to reveal genetic processes underlying ecosystem dynamics, which become further more recognized but yet remain poorly understood. In the present study we, therefore, make an attempt to revisit some earlier findings on complex dynamics of multilocus genetic systems with respect to their explanatory potential for ecosystem evolution. Namely, we address three following statements presented by Krassilov (1995, 2003, 2014a):

1. Ecosystem evolution is irreducible to dynamics of allele frequencies in populations within a community.

2. Release of genetic variation in populations within a community is determined and regulated by the type of ecosystem evolution, being higher under non-coherence compared to coherence.

3. Global ecosystems turnovers may be triggered by critical transitions in dynamics of allele frequencies in populations within a community. 


\section{Diverse dynamics of allele frequencies}

Following Dobzhansky (1937), evolution is commonly identified with a change in frequency of one allele relative to another. Within such approach, dynamics of allele frequencies is considered not as a necessary but the sufficient condition for evolution, in fact - as its definition. This seems to be an overstatement even for microevolution, not to speak of macroevolution ${ }^{1}$.

Fisher's fundamental theorem, saying that selection drives the genetic structure of a population towards a stable equilibrium point and increases the population mean fitness on the way, is proved to hold only for single-locus systems subjected to constant selection (Moran 1962). Infringing even one of these two restrictions (e.g., admitting either systems with two and more loci or temporarily varying selection) leads to lose in such a determinacy. Instead, much more sophisticated types of dynamics of allele frequencies, referred to as 'complex limiting behavior' (CLB), may appear. Thus, in multilocus systems, even when subjected to constant selection, trajectories of a population in space of allele frequencies are shown to converge to an equilibrium point only under very specific restrictions, e.g., under additive selection enabling Fisher's fundamental theorem (Kun \& Lyubich 1979). Likewise, diverse CLB patterns are long known to be caused by selection varying among phases of genetic structure (frequency-dependent selection), even when imposed to single-locus systems (Altenberg 1991).

In our earlier studies, we focused on models considering simultaneously several loci and cyclical selection, which are obviously more reasonable biologically (Kirzhner et al. 1994, 1996, 1998). For such models, CLB patterns, including stable ones, appeared rather abundant, up to cases where they predominated over 'traditional' movement towards simple dynamic patterns. The diversity of the observed CLB patterns included auto-oscillations with period equal to several ( $\mathrm{T}$-cycles) or hundreds to thousands (supercycles) periods of selection, auto-oscillations with oscillating period (super-supercycles), and even dynamics of allele frequencies unstable to small changes in initial conditions (dynamic chaos). An example of system with diverse dynamics of allele frequencies is shown in Fig. 1.

The models where CLB patterns were observed encompassed a rather broad spectrum of biological situations (Kirzhner et al. 1994, 1996, 1998), including:

- 1 locus with 4 alleles subjected to cyclical diploid selection; - 2 biallelic loci subjected to cyclical diploid selection;

- 4 unlinked biallelic loci subjected to stabilizing diploid $\underline{\text { selection with fluctuating optima; }}$

${ }^{1}$ The continuity of micro- and macroevolution has been a subject of a century long debates (Simons 2004). Although representatives of the Russian genetic school were highly cautious in this issue (Philipchenko 2011), Dobzhansky (1937) recognized no significant difference (except in time scale, which did not imply any inconsistency in research methodology). Krassilov avidly argues against expanding the laws of microevolution to macroevolution: since the former is a study of 'right now', such expanding is justified only if the latter is considered as a chaotic conglomerate of 'right now' events. Readiness to such a reducibility is easy to explain (e.g., by pragmatic philosophy reigning over the 20th century science) but hard to accept, since it implies denying long-term progressive evolution (Krassilov 2014b).

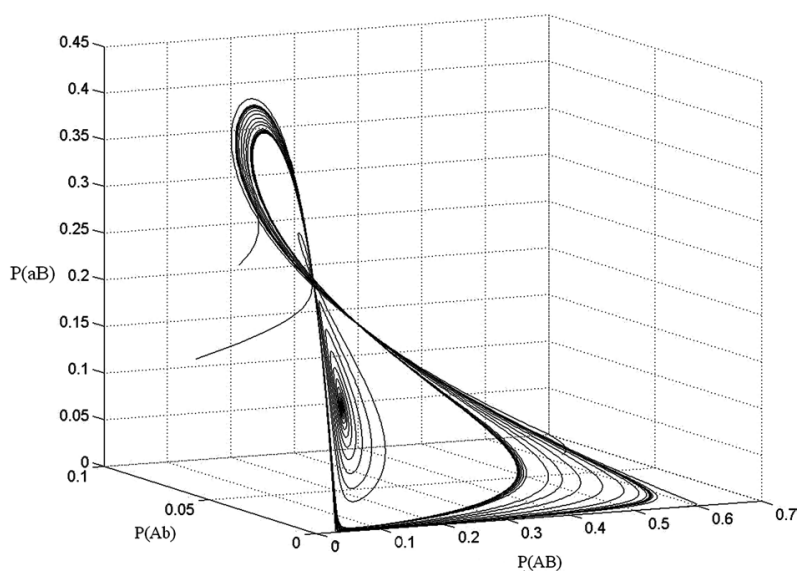

Figure 1 Phase portrait of a system with diverse dynamics of allele frequencies.

The genetic system consists of two selected loci, each with two alleles $(\mathrm{A} / \mathrm{a}$ and $\mathrm{B} / \mathrm{b})$. The environment changes cyclically, with two states favoring opposite allele combinations ( $\mathrm{AB}$ and $\mathrm{ab}$ vs $\mathrm{Ab}$ and $\mathrm{aB})$. The trajectories are shown in space of frequencies of three haplotypes, for the same state across the periods

- 4 linked biallelic loci subjected to stabilizing diploid selection with fluctuating optima;

- 4 linked biallelic loci subjected to stabilizing haploid selection with fluctuating optima;

- 2 unlinked blocks each of 2 linked biallelic loci subjected to stabilizing diploid selection with fluctuating optima;

- 2 unlinked blocks each of 2 linked biallelic loci subjected to stabilizing haploid selection with fluctuating optima.

Moreover, within these models, CLB patterns were observed under arbitrary wide ranges of genetic (e.g., rate of recombination, effects of loci on selected multilocus trait, and dominance effects within loci) and ecological parameters (e.g., period structure and trait optima at each environmental state).

\section{Effects of cogerence/non-coherence}

Evolution of biosphere is commonly believed to be a sequence of prolonged biospheric stases interspaced by relatively short biospheric crises (Butterfield 2007). According to Krassilov (1995, 2003), these two opposite modes are associated with respectively different patterns in ecosystem evolution: during a stasis, communities are stable, with established niche structure being maintained by strong stabilizing selection (coherence); while during a crisis, communities are highly dynamic, with fragile niche structure being rearranged due to directional selection (non-coherence).

On generalizing situations compatible with abundant CLB patterns, Kirzhner et al. $(1994,1996,1998)$ found that all of them required very strong selection, much stronger than one needed to maintain genetic polymorphism in the population. From this, it seems reasonable to infer that CLB patterns are more likely to be a characteristic of coherent ecosystem evolution. One more argument in favor of this assumption is the fact that CLB patterns were observed more frequently under low rates of recombination. Although the quantitative theory of fitness in fluctuating environments is still under elaboration (Sæther \& Engen 2015), the following 
general speculations seem plausible. As far as a community matures, diffusive competition strengthens, thereby feeding selection in favor of populations with lower genetic load, i.e., with higher mean fitness ${ }^{2}$. The latter, in its turn, implies lower rates of recombination, given the negative fitnessrecombination association (Fisher 1930).

On the other hand, non-coherence, with its drastic decrease in stabilizing selection, should be less compatible with CLB patterns. Also, directional selection for adaptive traits (which becomes prevalent under a community rebuilding, when populations race to occupy vacant niches) is known to favor higher rates of recombination (Charlesworth 1993, Korol 1994, 1999). The latter is remarkably in line with paleobotanical findings ascribing significant chronogeographic parallelisms in early angiosperms' morphology to the intensive gene transfer within the taxon during the Cretaceous-Paleogene crisis (Krassilov 2002). Indeed, recombination, mutation and gene transfer are mechanisms for release of genetic variation, and are therefore expected to show similar regularities (see inter alia Carja et al. 2014).

\section{Triggering ecosystem turnovers}

Since genetic polymorphism is a necessary condition for evolution of recombination, the above mentioned models compatible with stable CLB patterns were used to explore the dynamics of different alleles of rec-modifier - a selectively neutral locus affecting only rates of recombination between other loci. Considering a model systems heterogeneous at rec-modifier resulted in more complex dynamics of allele frequencies, compared to dynamics revealed in the same system when no difference in the rate of recombination among individuals was assumed. Specifically, in cases with traditional dynamics towards an equilibrium genetic structure, rec-modifier gave rise to supercycles; while in cases where supercycles already existed, super-supercycles and even chaos-like patterns emerged (Korol et al. 1998). An example of system with a supersupercycle caused by rec-modifier is shown in Fig. 2.

The revealed phenomenon may have significant consequences for the evolution of recombination. Cyclical selection usually favors higher rates of recombination less efficiently than directional selection (Charlesworth 1993); however, the longer period and the stronger selection are, the more cyclical selection resembles directional one (Otto \& Michalakis 1998). Thus, each transition to a new, more complex CLB pattern (T-cycle $\rightarrow$ supercycle $\rightarrow$ supersupercycle) generates additional periodicity in the system ${ }^{3}$; finally, the slowest of the waves determines the fate of rec-modifier, with respect to the "low-pass filter effect" of Sasaki \& Iwasa (1987).

\footnotetext{
${ }^{2}$ We consider fitness sensu lato, as including both (i) specific adaptations (matching the local environment, in terms of Gould 1976), and (ii) general adaptations like efficacy of essential metabolic pathways (matching the construction, in terms of Bauer 1935). The above mentioned increase in mean fitness under coherence is believed to occur for account of the second component, e.g., due to selection for higher efficiency of energy use (Parsons 2005)

${ }^{3}$ Remarkably, although such waves are virtual in a certain sense, their effect on recombination was analogous to the effect of superposition of two real environmental fluctuations (Korol et al. 1998).
}

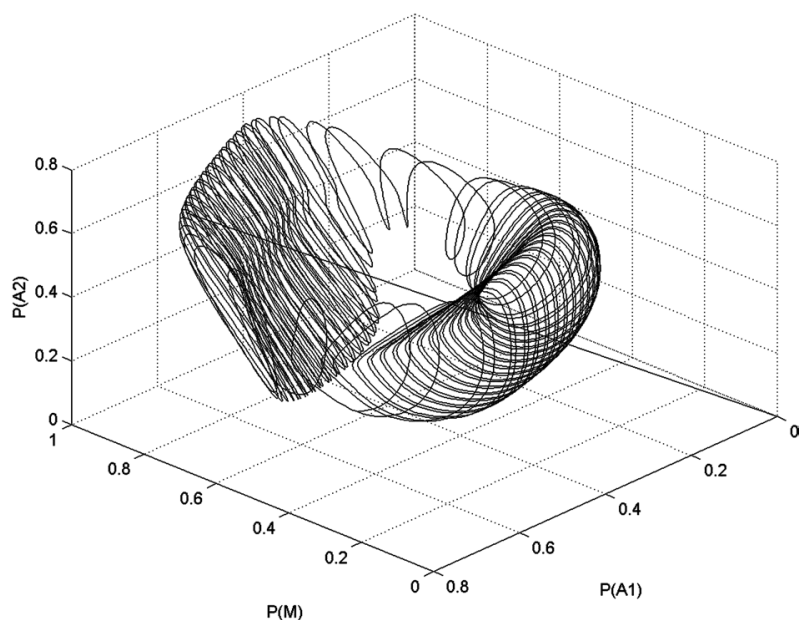

Figure 2 Phase portrait of a system with super-supercycle involving changes in rec-modifier allele frequencies.

The genetic system consists of two selected loci and selectively neutral rec-modifier locus, each with two alleles $(\mathrm{A} / \mathrm{a}, \mathrm{B} / \mathrm{b}$, and $\mathrm{M} / \mathrm{m}$ ). The environment changes cyclically, with two states favoring opposite allele combinations at selected loci ( $\mathrm{AB}$ and $\mathrm{ab}$ $\mathrm{vs} \mathrm{Ab}$ and $\mathrm{aB}$ ). The trajectories are shown in space of frequencies of alleles at three loci, for the same state across the periods

Besides, recombination-induced complication of dynamics of allele frequencies in a population may be considered as an additional factor triggering critical transitions in ecosystem evolution. Rotation theory of global change proceeds from the Earth's rotating forcing as the prime source for geological and, thereby, biological changes (Krassilov 2003). Although some stages of this causality (e.g., rotation forcing effects on tectonics, sea level fluctuations, volcanic activities, and climate) have recently obtained arbitrary empirical support (Krassilov \& Barinova 2013, Krassilov et al. 2014), the overall scheme is still poorly understood. In particular, it was suggested that ecosystem turnovers are triggered by a critical ratio between bio- and deadmass (Krassilov 1995, 2003). As a complementary hypothesis, we speculate that ecosystem turnovers may be facilitated by the revealed complicate effect of rec-modifier on dynamics of allele frequencies. Indeed, when such complication results in a chaotic CLB pattern, the population becomes hypersensitive to external disturbances in genetic structure. Therefore, even a very slight variation may lead the population to "fall" into a deep valley in its fitness landscape, causing decrease in fitness up to extinction. In case of population of a keystone species, such scenario immediately frees wide areas in niche structure of the community causing non-coherence (Krassilov 1995, 2003). It seems quite natural to expect analogous effects of other regulatory genes, e.g., ones affecting ratios between sexual and clonal reproduction in facultative parthenogens, or between outcrossing and selfing in facultative selfers (our preliminary surveys revealed certain similarities in behavior of these modifiers). Thus, in populations of an organism with complex sexual system (e.g., of a plant practicing simultaneously panmixia, selfing, and apomixis), complex CLB patterns with hypersensitivity are supposed to emerge even easier. If so, the complexity of regulatory system affecting release of genetic variation may itself be a subject to evolution, resulting in a balance between under- and overregulation. 


\section{Conclusions}

To conclude, revisited studies on CLB in multilocus genetic systems subjected to cyclical selection are consistent with the system theory of evolution in general, and of ecosystem evolution in particular. Obviously, bridging genetic and ecological models is only getting started now; however, the described framework seems to be rather effective. Our further studies will focus on other ecological aspects of evolution of recombination and sexual system, e.g., on evolution of condition-sensitivity of corresponding modifier systems and on their evolution in multispecies systems under antagonistic interactions.

\section{LITERAT URE CITED}

Altenberg, L. 1991. Chaos from linear frequency-dependent selection. American Naturalist 138(1):51-68.

Bauer, E.S. 1935. Theoretical Biology. Institute of Experimental Medicine, Moscow, Leningrad, 206 pp. (in Russian). Бауэр Э.С. 1935. Теоретическая биология. Москва; АенинграА: ИзА-во ВИЭМ. 206 с.].

Butterfield, N.J. 2007. Macroevolution and macroecology through deep time. Palaeontology 50(1):41-55.

Carja, O., U. Liberman \& M.W. Feldman 2014. Evolution in changing environments: modifiers of mutation, recombination, and migration. Proceedings of the National Academy of Sciences of the United States of America 111(50):1793517940.

Charlesworth, B. 1971. Selection in density-regulated populations. Ecology 52(3):469-474.

Charlesworth, B. 1993. Directional selection and the evolution of sex and recombination. Genetical Research 61(03): 205-224.

Dobzhansky, T. 1937. Genetics and the origin of species. Columbia University Press, New York, 364 pp.

Erwin, D.H. 2000. Macroevolution is more than repeated rounds of microevolution. Evolution \& Development 2(2): $78-84$.

Gladyshev, G.P. 1997. Thermodynamic Theory of the Evolution of Living Beings. Nova Science, Commack, NY, 142 pp.

Gould, S.J. 1976. This view of life: Darwin's untimely burial. Natural History 85(8):24-30.

Kirzhner, V.M., A.B. Korol, Y.I. Ronin \& E. Nevo 1994. Cyclical behavior of genotype frequencies in a two-locus population under fluctuating haploid selection. Proceedings of the National Academy of Sciences of the United States of America 91(24):11432-11436.

Kirzhner, V.M., A.B. Korol \& E. Nevo 1996. Complex dynamics of multilocus systems subjected to cyclical selection. Proceedings of the National Academy of Sciences of the United States of America 93(13):6532-6535.

Kirzhner, V.M., A.B. Korol \& E. Nevo. 1998. Complex limiting behaviour of multilocus genetic systems in cyclical environments. Journal of Theoretical Biology 190(3):215-225.

Korol, A.B. 1999. Selection for adaptive traits as a factor of recombination evolution: evidence from natural and experimental populations (a review). In: Evolutionary Theory and Processes: Modern Perspectives (S.P. Wasser, ed.), pp. 3153, Kluwer Academic Publishers, Dordrecht.

Korol, A.B., V.M. Kirzhner \& E. Nevo 1998. Dynamics of recombination modifiers caused by cyclical selection: interaction of forced and auto-oscillations. Genetical Research 72(02):135-147.

Korol, A.B, I.A. Preygel \& S.I. Preygel 1994. Recombination Vari- ability and Evolution. Chapman \& Hall, London, 361 pp.

Krassilov, V.A. 1995. Ecosystem and Egosystem Evolution. Pensoft, Sofia, $172 \mathrm{pp}$.

Krassilov, V.A. 2002. Character parallelism and reticulation in the origin of angiosperms. In: Horizontal Gene Transfer (M. Syvanen \& C.I. Kado, eds.), pp. 373-382, Academic Press, London.

Krassilov, V.A. 2003. Terrestrial Palaeoecology and Global Change. Pensoft, Sofia, 464 pp.

Krassilov, V.A. 2014a. On pragmatism, life, and evolution. International Journal of Philosophy 2(6):72-79.

Krassilov, V.A. 2014b. Evolution: System Theory. Pensoft, Sofia, $414 \mathrm{pp}$.

Krassilov, V. \& S. Barinova 2013. Sea level - geomagnetic polarity correlation as consequence of rotation geodynamics. Earth Science 2(1):1-8.

Krassilov, V., S. Barinova \& S. Rybnikov 2014. Rotation forcing of tectonics and climate. Earth Science 3(3):68-75.

Kun, L.A. \& Y.I. Lyubich 1979. Convergence to equilibrium under the action of additive selection in multilocus multiallele population. Doklady Akademii Nauk SSSR 249(5):10521054 (in Russian). [Кун А.А., Аюбич Ю.И. 1979. Сходимость к равновесию под Аействием аАдитивного отбора в полилокусной полиалмельной популяции // АокАаАы AH CCCP. T. 249, № 5. C. 1052-1054].

Laland, K.N., T. Uller, M.W. Feldman, K. Sterelny, G.B. Müller, A. Moczek \& J. Odling-Smee. 2015. The extended evolutionary synthesis: its structure, assumptions and predictions. Proceedings of the Royal Society B: Biological Sciences 282(1813):20151019.

Moran, P.A. 1962. The Statistical Processes of Evolutionary Theory. Oxford University Press, Oxford, 200 pp.

Nicolis, G. \& I. Prigogine 1977. Self-Organization in Nonequilibrium Systems: From Dissipative Structures to Order through Fluctuations. Wiley, New York, 512 pp.

Otto, S.P. \& Y. Michalakis 1998. The evolution of recombination in changing environments. Trends in Ecology \& Evolution 13(4):145-151.

Parsons, P.A. 2005. Environments and evolution: interactions between stress, resource inadequacy and energetic efficiency. Biological Reviews 80(4):589-610.

Philipchenko, Yu.A. 2011. Evolutionary Idea in Biology. Librokom, Moskva, 221 pp. (in Russian). [Филипченко Ю.А. 2011. Эволюционная идея в биологии. Москва: Аиброком. $221 \mathrm{c.}]$.

Sæther, B.E. \& S. Engen 2015. The concept of fitness in fluctuating environments. Trends in Ecology \& Evolution 30(5):273-281.

Sasaki, A. \& Y. Iwasa 1987. Optimal recombination rate in fluctuating environments. Genetics 115(2):377-388.

Schneider, E.D. \& J.J. Kay 1994. Complexity and thermodynamics: towards a new ecology. Futures 26(6):626-647.

Shapiro, J.A. 2011. Evolution: A Vien from the 21st Century. FT Press, Upper Saddle River, NJ, 272 pp.

Simons, A.M. 2002. The continuity of microevolution and macroevolution. Journal of Evolutionary Biology 15(5):688-701.

Weber, B.H., D.J. Depew, C. Dyke, S.N. Salthe, E.D. Schneider, R.E. Ulanowicz \& J.S. Wicken 1989. Evolution in thermodynamic perspective: an ecological approach. Biology and Philosophy 4(4):373-405.

Wicken, J.S. 1987. Evolution, Thermodynamics, and Information: Extending the Darwinian Program. Oxford University Press, Oxford, $258 \mathrm{pp}$. 


\section{Abraham Korol:}

I was first stricken by ideas of Valentin Krassilov in 1980s, while working on my monograph on the role of recombination in evolution and breeding in the Institute of Ecological Genetics in Chisinau. Unsurprisingly, being a geneticist first and foremost, I had only basic knowledge in paleontology. However, on reading his canonical textbook Evolution and Biostratigraphy (Nauka 1977), I felt inspired by to what extent we appeared congenial in recognizing non-randomness of evolution, although he came to it from macro-evolutionary viewpoint while I - from micro-evolutionary one. Long after, in early 2000s, being already a scholar of the Institute of Evolution in Haifa, he showed me another example of his impressive open-mindedness. It happened when he had appreciated my group's findings of slow population-genetics dynamics originating from rapid environmental fluctuations - he got inspired by this phenomenon, which seemed to him a promising bridge towards long-term ecosystem evolution. We sincerely hope that we will succeed in further contributing to new, holistic evolutionary biology that he indefatigably and cherishingly nurtured all his life. 